THE great importance
animals angplangthestant and microscopic
is noter layers in well estahlished. On the plankton plants,
chiefly consisting of diatoms, most of the animal life
in the sea is ultimately dependent for its food supply.
It is therefore natural that in fishery investigations,
when seeking the basal causes of fluctuations in supply
of fish, much time should have been spent in a study
of this drifting life.

For the past twenty-five years the European countries attached to the International Council for the Exploration of the Sea have carried out extensive programmes in the regions of the great sea fisheries, no small part of which have been concerned with plankton research. The course of such investigations naturally follows an evolutionary path, and, while the earlier years were spent in classifying the various species and noting their comparative abundance and distribution in different localities, the work is now tending to a more detailed and minute study of those few forms that have been proved, on account of their numbers and prevalence, to be of the greatest importance in the economy of the sea.

Such is the position on the European side of the North Atlantic ; but research is not so far advanced in the western Atlantic along the American seaboard. It is only in a recent publication ${ }^{1}$ that full details of the preliminary survey necessary to depict the general characters of the plankton, and to point out those species worthy of a more detailed study, are forthcoming.

The area dealt with in this report is the Gulf of Maine, the oceanic bight from Nantucket on the west to Cape Sable in Nova Scotia on the east. The survey has been very thoroughly carried out and brings out clearly the major fact that the characteristics of the plankton community are essentially the same as those long known to be the case in other boreal waters of the North Atlantic.

The report, which has been written by that distinguished American oceanographer, Dr. Henry B. Bigelow, is divided into two main portions, the first dealing with the animals of the plankton and the second with the plants. The outstanding feature of the animal plankton is the predominance of the small crustacean copepod Calanus finmarchicus. This small creature is indeed deserving of a wider apprecia. tion by the public, as it forms one of the main articles of food that constitute the links in the chain between plankton plants and fishes. Its abundance is overawing to the human mind; suffice it to say that in his largest catch Prof. Bigelow obtained upwards of $2,500,000$ individuals by towing a net with a circular opening of one metre diameter through the sea for fifteen minutes. This huge catch shows that the region under observation can hold its own with the richest waters on the eastern side of the Atlantic, the largest catch the present writer is aware of being recorded by Hjort in "The Depths of the Ocean," p. 726, namely, at least $2,000,000$ in a ten minutes' haul with a similar net to that mentioned above. Prof. Bigelow gives an instructive chart which emphasises clearly the predominance of this crustacean over other animals in the plankton.

In the catches also appear, in smaller and varying numbers, several species that characterise the collections, notably the copepods Metridia lucens

1 "Plankton of the Offshore Waters of the Gulf of Maine." By Henry B. Bigelow. Bulletin of the Bureau of Fisheries, vol. 40, 1924, part 2, Document No. 968, pp. 1-509. Washington, 1926.

\section{Gulf of Maine.}

and Pseudocalanus elongatus, the 'glass-worm' Sagitta elegans, the amphipod genus Euthemisto, the euphausiid genera Thysanoessa and Meganyctiphanes; the pteropod Limacina retroversa, the ctenophore Pleurobrachia pileus, and in deeper water the large copepod Euchæta. These organisms are here together designated the 'Calanus community.' Mention should be made of the euphausiid group ; these shrimp-like animals are of considerable size compared with the other members of the plankton, Meganyctiphanes reaching a length of an inch or more, and their importance as food for fishes is being increasingly realised. There are few fish from northern waters, indeed, that have not been found feeding on them, and they form the chief food of the whalebone whales, the distribution of which in the Norwegian Sea has recently been shown by Hjort in a preliminary survey (Cons. Intern. pour l'Explor. de la Mer, Rapp. et Proc. Verb., vol. 41, 1927, p. 115) to coincide at times with that of Meganyctiphanes. In this connexion Dr. Bigelow gives two interesting photographs of the fringe of whalebone plates, showing how the coarser fringe of the fin-back whale (Balcenoptera physalus) allows the smaller animals of the plankton to pass through, the larger organisms, such as the euphausiids, alone being retained, while the fine fringe of the bone of the pollock whale (Balcenoptera borealis) is able to retain in addition large quantities of the copepod Calanus.

Besides the species mentioned above, all animals present in the collections are dealt with in detail in the report as regards their seasonal and regional distribution. In the work of identification the author received the assistance of Prof. C. B. Wilson, but although relieved of this labour, Dr. Bigelow's report must represent the results of a vast amount of careful thought and study.

In dealing with the plants, or phytoplankton, for identification of which the author was indebted to Dr. Albert Mann, it is evident that far less information was available than in the case of the animals. Nevertheless, it is sufficient to show that in their general trend of behaviour the plants follow the same course in their seasonal distribution as they do in European waters. There is a very abundant plankton of diatoms in early spring which dies down and is succeeded in the summer months by a less abundant peridinian plankton.

At the end of this second portion of the report, Dr. Bigelow gives a valuable discussion on the problems connected with the cycle of events characteristic of phytoplankton throughout the seasons, in which a summary of much of the modern literature on the subject is included. The importance of those possible limiting factors in the environment, such as phosphates, nitrates, and silicates, is discussed, but the reader is left with the realisation that much work must be carried out before the various phenomena can be thoroughly understood. Unfortunately, no work on the phosphate and nitrate content of the sea-water comparable to that of Atkins and Harvey at Plymouth, and more recently Marshall and Orr at Millport, has yet been carried out in the region under survey.

Dr. Bigelow is to be congratulated on producing an addition to the literature that will prove invaluable to many plankton workers. The report is illustrated with many beautiful photographic plates reminiscent of those produced by the school of marine biologists at Port Erin, and contains an extremely useful bibliography of 365 titles.
F. S. R. 